\title{
Instituições Internacionais de Saúde no Contexto Sub-Regional
}

\author{
International Health Institutions in the Sub- Regional Context
}

Instituciones Internacionales de Salud en el contexto subregional

\author{
Roberta de Freitas Campos ${ }^{1}$ \\ Sueli Gandolfi Dallari²
}

RESUMO. Introdução: ao que pese as diferenças nucleares entre os blocos União Europeia (UE) - supranacional e União das Nações Sul-americanas (UNASUL) intergovernamental, em ambos as competências regionais em matéria sanitária não se sobrepõe às competências dos Estados-membros. No caso da União Europeia os art. 4, §2, k; art. 6, a; art. 168 do Tratado sobre o Funcionamento da UE confere apenas poderes para agir em complemento das políticas nacionais; enquanto na União de Nações Sul-americanas, nos artigos $2^{\circ}$ e $3^{\circ}$, f de seu Tratado Constitutivo prevê como objetivo construir, de maneira participativa e consensuada, um espaço de integração, para que de forma consequente os Estados independentes possam garantir o acesso universal aos serviços de saúde às suas populações. Dessa forma, o objetivo é verificar as competências, a constituição histórico-regional, objetivos e potencialidades dessas instituições internacionais, criadas no âmbito desses blocos regionais, em influenciar as políticas regionais e nacionais de saúde. Metodologia: tendo em vista a ampla gama de instituições internacionais que atuam de forma multisetorial na saúde, o estudo apresenta aqueles órgãos cujas competências são estabelecidas nos tratados constitutivos e decisões presidenciais e resoluções desses blocos. Para isso foi realizada uma pesquisa documental e bibliográfica no âmbito das Instituições da União Europeia e da Unasul. Resultados e Conclusão: um importante ponto de questionamento diz respeito à existência ou não de um diálogo entre essas instituições e os cidadãos dos blocos a que pertencem, uma vez que se parte do pressuposto que a democracia deve ser uma regra implícita no 'jogo' internacional.

Palavras-chave: Diplomacia em Saúde. Instituições internacionais. União Europeia.

ABSTRACT. Introduction: despite nuclear differences between the European Union (EU) - supranational and the Union of South American Nations (UNASUR) intergovernamental blocks, in both regional health skills do not override the competences of the Member States. In the case of the European Union art. 4, § 2, k; art. 6, a; art. 168 of the Treaty on the Functioning of the EU, it gives only empowered to act as a complement to national policies; while in the Union of South American Nations, in articles 2nd and 3rd, $f$ of its Constitutive Treaty, it stipulates the objective of building in a participatory and consensual manner an area of integration, so that consistently

\footnotetext{
1 Doutoranda da Faculdade de Saúde Pública - FSP/USP e Pesquisadora do Núcleo de Estudos sobre Bioética e Diplomacia em Saúde da Fundação Oswaldo Cruz - Nethis/Fiocruz. Apoio Capes/CNPq.

2 Coordenadora do Núcleo de Pesquisas em Direito Sanitário da Universidade de São Paulo Napdisa/FSP/USP.
} 
independent States can ensure universal access to health services to their populations. In this way, the aim is to check the powers, the regional historical Constitution, goals and potential of these international institutions, created within the framework of those regional blocs, in influencing the regional and national health policies.

Methodology: in view of the wide range of international institutions that act in a multisectoral form in health, the study presents those bodies whose competences are laid down in the founding treaties and presidential decisions and resolutions of these blocks. Results and Discussion: thus it was done a bibliographical and documentary research within the EU and Unasur institutions. An important point of questioning relates to whether or not there is a dialogue between these institutions and the citizens of the blocks to which they belong, since it is assumed that democracy must be an implicit rule in the international "game".

Keywords: Health Diplomacy. International Institutions. European Union.

RESUMEN. Introducción: a pesar de las diferencias nucleares entre los bloques de la Unión Europea (UE) - supranacional y la Unión de las Naciones Sud-americanas (UNASUL) - intergubernamental, en ambos las competencias regionales en materia sanitaria no se sobrepone las competencias de los Estados-miembros. En el caso de la Unión Europea los art. 4, §2, k; art. 6, a; art. 168 del Tratado sobre el Funcionamiento de la UE confiere apenas poderes para actuar en complemento de las políticas nacionales; mientras en la Unión de Naciones Sud-americanas, en los artículos $2^{\circ}$ y $3^{\circ}$, f de su Tratado Constitutivo predice como objetivo construir, de manera participativa y consensual, un espacio de integración, para que de forma consecuente los Estados independientes puedan garantizar el acceso universal a los servicios de salud a su población. Metodología: de esa forma, el objetivo es verificar las competencias, la constitución histórico-regional, objetivos y potencialidades de esas instituciones internacionales, creadas en el ámbito de esos bloques regionales, en influenciar las políticas regionales y nacionales de salud. Dada la amplia gama de instituciones internacionales que actúan de forma multisectorial en la salud, el estudio presenta aquellos organismos cuyas responsabilidades son establecidas en los tratados constitutivos y decisiones presidenciales y resoluciones de esos bloques. Para eso fue realizada una investigación documental y bibliográfica en el ámbito de las Instituciones de la Unión Europea y de la Unasul. Resultados y Discusión: un importante punto de cuestionamiento dice respecto a la existencia o no de un dialogo entre esas instituciones y los ciudadanos de los bloques a los que pertenecen, una vez que se asume que la democracia debe ser una regla implícita en el "juego" internacional.

Palabras-Ilave: Diplomacia en Salud. Instituciones internacionales. Unión Europea.

\section{Introdução}

O seguinte trabalho apresenta resultados preliminares da pesquisa em curso no Programa de Pós-graduação Doutorado em Saúde Global e Sustentabilidade da Faculdade de Saúde Pública da Universidade de São Paulo sobre as principais 
instituições internacionais que atuam na temática da saúde nos blocos União Europeia (UE) e União das Nações Sul-americanas (UNASUL).

A importância da saúde na agenda das relações internacionais, associada a questões de segurança nacional e do comércio internacional, é reconhecida desde o Século XVII com ações voltadas para o controle das 'ameaças', tais como epidemias e doenças, que poderiam comprometer interesses materiais específicos (comércio internacional e acúmulo de riqueza) e as estratégias de dominação entre os países (1).

O destaque nessa correlação vem sendo ampliado ao longo dos anos, por fatores impulsionados pelo processo de globalização e pelas mudanças geopolíticas (2) (3).

La globalización modifica la naturaleza de las necesidades en salud, así como el tipo de intervenciones adecuadas para satisfacerlas. Las comunidades, además de afrontar los problemas locales relacionados con sus sistemas de salud, también deben hacer frente a la transferencia internacional de riesgos para la salud. Es por eso que la globalización, si no introduce, al menos acentúa desafíos tales como La necesidad de mancomunar esfuerzos internacionales para reducir riesgos y aprovechar las oportunidades sanitarias para garantizar el derecho a la salud (4).

Almeida (1) e Kerouedan (5) apontam que com a globalização a saúde passou a integrar as agendas do G-8, do Conselho de Segurança e da Assembleia Geral das Nações Unidas como tema relacionado a segurança global.

Da mesma forma, os processos de integração regional entre países, partem do pressuposto de que alianças regionais potencializam a capacidade de resolução de problemas, fortalecem a integração e/ou a cooperação política e econômica e melhoram a estratégia negociadora internacional. Nessa perspectiva, a integração e a cooperação regional constituem um objetivo estratégico.

Em geral e ao longo dos anos, esses processos também foram motivados por questões geopolíticas e pelo estabelecimento de relações econômicas e comerciais privilegiadas. Entretanto, ao longo dos anos se observa a inclusão do tema da saúde com aspectos sociais na agenda dos blocos de integração, estabelecendo-se, assim instituições e mecanismos para operacionalizá-los. Uma das experiências mais maduras sub-regional, a União Europeia (UE) "has an economy that is anchored on neo-liberal foundations, it also has a cherished social system rooted in robust precepts of social democracy" (6). 
Os processos de integração regional funcionam como espaços de atuação da diplomacia da saúde ${ }^{3}$. São nessas esferas em que se verificam os mais diversos interesses e atores. Para Habermas, existem duas formas básicas de integração de um sistema de ação, que poderia ser utilizado para compreender a propostas em curso de integração regional:

- Integração obtida através de um consenso alcançado normativamente ou comunicativamente (Integração social);

- Integração obtida através de uma regulação não normativa das decisões individuais que vai além da consciência dos atores, via mecanismos autoregulados como o mercado, ou a burocracia (Integração sistêmica).

Se pode observar formas de caracterizar a União Europeia: aquelas que salientam as características da EU como uma organização supranacional e aquelas que salientam características como uma ordem jurídica constitucionalizada ou 'system of governance'. A compreensão dos efeitos da União Europeia em matéria do direito à saúde seria incompletos se ignorasse o fato que em muitos aspectos ela atua como uma organização intergovernamental:

\begin{abstract}
Although the range of actions to be taken by the European Union in the area of health protection has been broadened by the 1997 Treaty of Amsterdam, topics relating to the structure of health care systems, quality of care and patients' rights remain to a large extent in the formal domain of national authorities. The responsibility of the European Union is to support instead of initiate or force national initiatives. However, regarding these topics, it is unavoidable to think about and to develop normative frameworks in an international context. (7)
\end{abstract}

Ao que pese a diferenças entre os países da EU e Unasul, um ponto em comum em ambas é sua aspiração em aumentar cooperação na área da saúde. Nesse sentido, a integração, por sua vez, pressupõe cooperação internacional:

En la concepción de las relaciones internacionales basada en la clásica dicotomía entre interacciones de conflicto e interacciones de cooperación, la integración se ubica, por consiguiente, dentro de este segundo grupo de formas de relación entre los Estados. Su función primordial, desde el punto de vista de los fines de la política internacional, consiste en la identificación racional de materias y procedimientos de relación entre los Estados de naturaleza preferentemente cooperativa. (8)

\footnotetext{
3 Segundo KICKBUCH (2010) diplomacia da saúde trata dos processos de negociação que configuram e gerenciam o ambiente da política global para a saúde e seus determinantes.
} 
Cada organização regional é diferente, e as organizações a desenvolver as suas próprias iniciativas e ferramentas que são adaptados para responder às necessidades e desafios específicos também. Mas o que está subjacente a eficácia de tais instrumentos e mecanismos é que eles estejam amparados por regras e políticas muito robustas (6).

A saúde é uma área vital e nenhum país pode lidar individualmente com os problemas específicos de saúde. Ações coletivas, especialmente a nível regional, são relevantes, as condições de difusão dos acordos regionais incluindo vontade, aceitação e capacidade das entidades regionais merecem ser estudadas.

A perspectiva da cooperação nesta área implica o intercâmbio de experiências e a cooperação quanto à formulação de políticas e legislação condizente com este objetivo, esquemas de financiamento de sistemas universais e modelos de atenção, incluindo a atenção primária de saúde e outros níveis de complexidade, assim como a atenção individual e coletiva. (9)

A importância crescente da análise de políticas de saúde no contexto internacional exige cada vez mais uma ampla perspectiva sobre os componentes relevantes. Para que as políticas regionais de saúde surtam efeito alguns fatores devem ser considerados. Num primeiro momento a necessidade de regras e políticas que podem estar contidas nos Tratados, Protocolos, Resoluções, Declarações, etc. Incluindo na definição dessas políticas as competências das instituições nesses blocos que as define:

También es importante destacar otros enfoques analíticos o, por lo menos, preocupaciones más o menos sistemáticas sobre determinados aspectos políticos de la integración regional. Uno de ellos se refiere al examen de la función de las instituciones o los órganos de los sistemas institucionales de los esquemas de integración como medios para confrontar los intereses nacionales y, en especial, para procesar los intereses comunes. (8)

Também no que se refere a participação cidadã como ator com interesse primário e necessário, uma vez que nesses contextos sub-regionais, organizações como a União Europeia e Unasul desempenham um papel importante, nas intervenções legais e definições políticas que afetam seus cidadãos:

Even if there is the will to act in terms of norms and visionary leadership in engineering regional social policies, this will not happen if structures are not in place to internalize such regional standards. That is why it is useful to imbue a sense of legitimacy or credibility to the social policy 
promotion process. This is epitomized by the concept of acceptance. The condition of acceptance is crucial because in its absence, it will be difficult to invoke the possibility of an effective regional social policy. Factors that are vital in terms of acceptance include openness to learn, awareness by a broad spectrum of citizens, the degree of compliance with regional disciplines as crafted, and the propensity for engagement of the regional entity in interactions with global or international socially relevant institutions. (6)

\section{Instituições de Saúde da União Europeia}

Para se identificar os objetivos, competências e potencialidades das instituições da União Europeia que atuam em matéria de Saúde, faz-se necessário, inicialmente, esclarecer alguns pontos específicos.

\section{A - Possibilidade de estabelecimento de normas conhecidas como direito europeu derivado}

De forma resumida o direito comunitário, atualmente conhecido como direito europeu, se divide em direito primário e derivado. Sendo os tratados constitutivos ou 'fundadores' que enunciam a repartição de competências entre a União e os EstadosMembros e estabelecem os poderes das instituições europeias como fontes do 'direito primário'. Esses tratados, assim como aqueles tratados modificativos da EU, os protocolos anexados e os tratados de adesão dos Estados-Membros, determinam 0 quadro jurídico no âmbito do qual as instituições da UE aplicam as políticas europeias.

O 'direito derivado' inclui os atos unilaterais provenientes das próprias instituições da EU, que constam da nomenclatura do artigo 288. do Tratado sobre o Funcionamento da UE: regulamentos, diretivas, decisões, pareceres e recomendações, além de atípicos como comunicações, as recomendações e outros.

Nos Estados membros da União Europeia a responsabilidade pela saúde não se encontra unicamente alocada às suas instituições nacionais, mas em algumas circunstancias podem assentar-se nas instituições da União Europeia ou em interações entre ambas (10).

As três principais instituições da UE envolvidas no processo legislativo são o Parlamento Europeu, O Conselho da União Europeia e a Comissão Europeia. 
Em conjunto, estas três instituições adoptam, através do processo legislativo ordinário ${ }^{4}$, as políticas e a legislação que se aplicam em toda a UE. Em princípio, a Comissão propõe nova legislação e o Parlamento e o Conselho adotam-na. A Comissão e os Estados-Membros são os responsáveis pela sua execução. A Comissão vela também pela transposição da legislação da UE para as ordens jurídicas nacionais.

Essas instituições legislativas possuem competências limitadas, podendo agir somente nas áreas ou temas onde os Tratados Ihe garantam formalmente poderes. Todos esses atos (regulamentos, diretivas, decisões, etc.) podem ser revistos quanto a sua forma e conteúdo pelo Tribunal de Justiça da EU. Importante, ainda, esclarecer que diferentes atos dessas instituições possuem diferentes efeitos nos sistemas jurídicos e de saúde nacionais.

Desse modo qualquer ato normativo oriundo das instituições da União Europeia em matéria de saúde deve ter sua previsão de competência definida nos tratados que as constituem.

\section{B - Evolução da temática de saúde na União Europeia}

Com o entusiasmo da criação da Comunidade Econômica do Carvão e do Aço (CECA) várias propostas para a nova comunidade europeia surgiram: comunidade europeia da defesa, comunidade política bem como um projeto preliminar de comunidade em matéria de saúde, lançada pelo então ministro francês Paul Ribeyre em 1952, que era centrada em três elementos: mercado comum dos profissionais de saúde e produtos para a saúde; cooperação muito avançada em matéria de formação, pesquisa e ações sanitárias; progressiva unificação dos regimes de seguridade social (11).

Esse projeto não foi adiante, sendo necessário compreender a forma como os tratados foram abordando a preocupação comunitária em matéria de saúde em sua evolução.

\footnotetext{
${ }^{4}$ No início, o Tratado de Roma de 1957 deu ao Parlamento um papel consultivo no processo legislativo: a Comissão propunha e o Conselho adotava a legislação. O Ato Único Europeu (1986) e os Tratados de Maastricht, de Amsterdam, de Nice e de Lisboa, sucessivamente, alargaram as prerrogativas do Parlamento. Agora pode colegislar em pé de igualdade com o Conselho na grande maioria dos domínios. Implica a intervenção do Parlamento Europeu enquanto colegislador a par do Conselho. http://www.europarl.europa.eu/aboutparliament/pt/20150201PVL00004/Poderes-legislativos.
} 
Os tratados originais CECA de 1951 e Comunidade Económica Europeia (CEE) e Comunidade Europeia da Energia Atómica (CEEA ou Euratom) de 1957, abordam a saúde com uma aproximação estritamente defensiva (12), essencialmente no que diz respeito a preocupação com a saúde e segurança dos trabalhadores, conforme quadro abaixo:

Quadro 1 - Evolução da temática de saúde na União Europeia

\begin{tabular}{|c|c|c|}
\hline Tratado & Dispositivo & Texto do Tratado \\
\hline \multirow{2}{*}{ CECA, 1951} & Art. 46, §5 & $\begin{array}{l}\text { "Reunir informações necessárias para avaliação das } \\
\text { possibilidades de melhora das condições de vida e trabalho dos } \\
\text { trabalhadores nas indústrias de sua competência e dos riscos } \\
\text { que decorrem dessas condições de vida" }\end{array}$ \\
\hline & Art. 55, §1 & $\begin{array}{l}\text { "A alta autoridade deverá fomentar a investigação técnica e } \\
\text { econômica relacionada com a produção e consumo de carvão e } \\
\text { aço, bem como a segurança no trabalho dessas industrias." }\end{array}$ \\
\hline \multirow[b]{2}{*}{ CEE, 1957} & Art. 117 & $\begin{array}{l}\text { "Os Estados-membro acordam sobre a necessidade de } \\
\text { promover a melhora das condições de vida e trabalho dos } \\
\text { trabalhadores a fim de conseguir sua equiparação por via do } \\
\text { progresso." }\end{array}$ \\
\hline & Art. 118 & $\begin{array}{l}\text { "(...) a Comissão terá por missão promover uma estreita } \\
\text { colaboração com os Estados-membros no âmbito social, } \\
\text { particularmente nas matérias relacionadas a: } \\
\text { - Direito ao Trabalho e condições do trabalho; } \\
\text { - Proteção contra acidentes de trabalho e doenças profissionais; } \\
\text { - Higiene do trabalho. }\end{array}$ \\
\hline \multirow[b]{2}{*}{$\begin{array}{l}\text { CEEA, } \\
1957\end{array}$} & Art. 2, b) & $\begin{array}{l}\text { Para o cumprimento da sua missão, a Comunidade deve, nos } \\
\text { termos do disposto no presente Tratado: b) Estabelecer normas } \\
\text { de segurança uniformes destinadas à proteção sanitária da } \\
\text { população e dos trabalhadores e velar pela sua aplicação. }\end{array}$ \\
\hline & Art. 30 & $\begin{array}{l}\text { Serão estabelecidas na Comunidade normas de base relativas à } \\
\text { proteção sanitária da população e dos trabalhadores contra os } \\
\text { perigos resultantes das radiações ionizantes. Entende-se por } \\
\text { «normas de base»: } \\
\text { a) As doses máximas permitidas, que sejam compatíveis com } \\
\text { uma margem de segurança suficiente; } \\
\text { b) Os níveis máximos permitidos de exposição e contaminação; } \\
\text { c) Os princípios fundamentais de vigilância médica dos } \\
\text { trabalhadores. }\end{array}$ \\
\hline
\end{tabular}

Fonte: Tratado CECA, Tratado CEE, Tratado CEEA ou EURATOM ${ }^{5}$

\footnotetext{
${ }^{5}$ Comunidade Europeia do Carvão e Aço. Tratado que institui a Comunidade Europeia do Carvão e do Aço (Tratado CECA), 1951.Disponível em:< http://eur-lex.europa.eu/legalcontent/PT/TXT/HTML/?uri=URISERV:xy0022\&from=ES >. Acesso em: 09 jul. 2014.

Comunidade Económica Europeia. Tratado que institui a Comunidade Económica Europeia ou Tratado CEE - texto original (versão não consolidada),1957. Disponível em: < http://eur-lex.europa.eu/legalcontent/PT/TXT/HTML/?uri=URISERV:xy0023\&from=ES>. Acesso em: 09 jul. 2014.
} 
O Ato Único Europeu de 1986, constituiu uma etapa importante ao modificar os tratados e incluir competências em matéria de saúde, ainda que não de forma direta (12); (11), três destaques possuem objetivos relacionados a saúde pública:

Quadro 2 - Saúde e temas correlatos no TCEE

\begin{tabular}{|l|l|l|}
\hline \multicolumn{1}{|c|}{ Tema } & $\begin{array}{c}\text { Dispositivos } \\
\text { incluídos }\end{array}$ & \multicolumn{1}{c|}{ Texto do Tratado } \\
\hline $\begin{array}{l}\text { Política de } \\
\text { meio } \\
\text { ambiente }\end{array}$ & Art. 130 R & $\begin{array}{l}\text { 1. A ação da Comunidade em matéria de ambiente tem por } \\
\text { objetivo: } \\
\text { - preservar, proteger e melhorar a qualidade do ambiente; } \\
\text { - contribuir para a proteção da saúde das pessoas; } \\
\text { - assegurar uma utilização prudente e racional dos recursos } \\
\text { naturais }\end{array}$ \\
\hline $\begin{array}{l}\text { Política } \\
\text { Social }\end{array}$ & Art. 118 A & $\begin{array}{l}\text { 1. Os Estados-membros empenham-se em promover a } \\
\text { melhoria, nomeadamente das condições de trabalho, para } \\
\text { protegerem a segurança e a saúde dos trabalhadores, e } \\
\text { estabelecem como objetivo a harmonização, no progresso, das } \\
\text { condições existentes nesse domínio. }\end{array}$ \\
\hline $\begin{array}{l}\text { Mercado } \\
\text { Interior }\end{array}$ & Art. 100 A & $\begin{array}{l}\text { 3. A Comissão, nas suas propostas previstas no no1 em } \\
\text { matéria de saúde, de segurança, de proteção do ambiente e de } \\
\text { proteção dos consumidores, basear-se-á num nível de } \\
\text { proteção elevado. }\end{array}$ \\
\hline
\end{tabular}

Fonte: Tratados que instituem as Comunidades Europeias ${ }^{6}$

O Tratado de Maastricht, 1993, que institui a Comunidade Europeia (depois União), representa um marco fundamental ao incluir como um de seus objetivos a "contribuição para a realização de um elevado nível de proteção da saúde" (Art. 3, o). Esse tratado, ainda, inclui um título específico (Art.129) como base legal explícita das competências em matéria de saúde pública.

A inclusão desse artigo pode se relacionar com a percepção dos Estados-membros de que alguns problemas de saúde não podem ser solucionados somente dentro de suas fronteiras, como por exemplo na época as epidemias relacionadas ao HIV/AIDS. De forma alternativa ou adicional pode estar relacionada a preocupação dos Estados-

Comunidade Europeia da Energia Atómica. Tratado que institui a Comunidade Europeia da Energia Atómica (Euratom), $1957 . \quad$ Disponível em: < http://eur-lex.europa.eu/legalcontent/PT/TXT/HTML/?uri=URISERV:xy0024\&from=PT >. Acesso em: 09 jul. 2014.

${ }^{6}$ União Europeia. Tratados que instituem as Comunidades Europeias: Tratados que alteram esses tratados. Acto único Europeu. 1987. Vol. I. 1128 p. 
membros em limitar a competência da EU em matéria de saúde, reflexo de atividades que já vinham acontecendo ${ }^{7}$ :

Some subsequent activity involving coordination of policies between the Member states in the field of health, predating the inclusion of specific legal basis provisions on health in the Treaty. For instance, the Europe against Cancer programme was established in 1989 and the Europe against AIDS programme in 1991. As the enactment of these measures pre-dated any formal competence on the part of the Community to take such action. (10)

Destacamos que a revisão do art. 129 do Tratado de Maastricht pelo Art. 152 do Tratado de Amsterdã, 1997, fruto da epidemia da 'vaca louca' ou BSE ${ }^{8}$, alertou que os perigos para a saúde transfronteiriços se desenvolvem numa proporção cada vez maior, e incitou a União Europeia quanto a necessidade de adotar um papel mais importante na promoção e coordenação de soluções de cuidados de saúde para todos os cidadãos da União, concentrando-se na prevenção de doenças, na preparação global e numa rápida reação em caso de perigos potenciais.

Segundo Hervey e McHale (10) tal modificação ampliou as competências da União Europeia de 'contribuir para um elevado nível de proteção da saúde humana' para 'assegurar um elevado nível de proteção da saúde'.

A essência desse artigo incide em definir, naquele momento, as medidas legislativas que o Conselho da EU poderia adotar ${ }^{9}$. Bem como as recomendações propostas pela Comissão para os fins do artigo. Dessa forma, o Conselho adotou resoluções concretizando diversos programas de ação da Comissão incluindo, por exemplo: Programas de saúde relacionados a AIDS, câncer, drogas, prevenção,

\footnotetext{
7 Baseadas na interpretação do art. 235, TCEE, 1957 "Quando uma ação da Comunidade resulte necessária para alcançar, no funcionamento do mercado comum, um dos objetivos da comunidade, sem que o presente Tratado tenha previsto os poderes de ação necessários, o Conselho, por unanimidade, a proposta da Comissão e prévia consulta a Assembleia, adotará as disposições pertinente. "

${ }^{8}$ A crise da BSE levou a União Europeia a proibir as exportações de carne britânica por 10 anos, com efeitos a partir de Março de 1996.

9 "Art. 152, §4, a) Medidas que estabeleçam normas elevadas de qualidade e segurança dos órgãos e substâncias de origem humana, do sangue e dos derivados do sangue; essas medidas não podem obstar a que os Estados-Membros mantenham ou introduzam medidas de proteção mais estritas; b) Medidas nos domínios veterinário e fitossanitário que tenham diretamente por objetivo a proteção da saúde pública; c) Ações de incentivo destinadas a proteger e melhorar a saúde humana, com exclusão de qualquer harmonização das disposições legislativas e regulamentares dos Estados-Membros".
} 
doenças raras, monitoramento em saúde e Programas de Ação em matéria de Saúde Pública para a promoção, informação, educação e capacitação ${ }^{10}$.

A UE preservou as responsabilidades dos Estados-Membros em matéria de organização e prestação de serviços de saúde e de cuidados médicos (Art. 152, §5).

O tratado de Lisboa ${ }^{11}$ que revisou as competências, instituições e formas de atuação da União Europeia; buscou torna-la mais democrática, eficaz e mais apta a resolver problemas a nível mundial, como as alterações climáticas, epidemias, e outras questões para além dos objetivos econômicos previstos inicialmente nesse bloco.

Ao que pese críticas $^{12}$, esse tratado trouxe mudanças no reforço dos poderes do Parlamento Europeu (substituiu o processo de co-decisão pelo processo legislativo ordinário que inclui a intervenção do Parlamento Europeu enquanto colegislador junto com o Conselho da EU), na alteração dos procedimentos de votação no Conselho, e na inclusão de mecanismos de participação cidadã na iniciativa de proposta legislativa à Comissão ${ }^{13}$.

Entretanto, os mecanismos que garantam a participação dos cidadãos nas tomadas de decisão se dão apenas de forma "tão próxima quanto possível" (Art. 10, §3), vez que a União Europeia se baseia na democracia representativa, e sua única Instituição necessariamente nesses moldes é o Parlamento Europeu.

\section{C - As Instituições}

Hoje, a saúde é vista não só como uma área política separada e claramente definida, mas também como um aspecto importante de outras áreas, tais como a agricultura, o ambiente, o emprego, a concorrência, a proteção do consumidor, etc.

O Tratado de Lisboa clarifica a repartição de competências da EU; dos países da EU e compartilhadas. Dessa forma, a competência atual da UE frente a problemas

\footnotetext{
10 Decisão 646/96/EC, OJ 1996 L95/9; Decisão 647/96/EC, OJ 1996 L95/16; Decisão 102/97/EC, OJ 1997 L19/25; Decisão 645/96//EC, OJ 1996 L95/1; Decisão 372/99/EC, OJ 1999 L46/1; Decisão 1400/97/EC, OJ 1997 L193/1.

11 Foi amplamente discutido desde 2004, adotado em 2007 e em vigor desde 2009.

12 HABERMAS, J. Sobre a Constituição da Europa: um ensaio. São Paulo. Ed. Unesp, 2012.

13 Tal procedimento previsto no Art. 11, $\$ 4$ e Art. 24 delega ao Parlamento e Conselho a adoção de regulamentos para esse dispositivo, mencionando apenas a necessidade de que a proposta tenha número mínimo de 1 milhão de cidadãos europeus distribuídos em número mínimo de Estados-Membros.
} 
comuns de segurança em matéria de saúde pública ${ }^{14}$ é compartilhada com os EstadosMembros ${ }^{15}$ conforme os aspectos definidos no Art. 168 do Tratado de Funcionamento da União Europeia.

Nos temas de saúde pública (...) a organização regional depende da transversalidade que caracteriza o direito internacional geral. Por não ter uma competência direta em matéria sanitária, o recurso legislativo de que se vale a UE é justamente a Diretiva comunitária, um tipo de norma de harmonização das normas nacionais que, mesmo depois de aprovada pelos Estados-membros, requer a transposição de seu conteúdo normativo às respectivas ordens internas. (13)

Em matéria de proteção e melhoria da saúde ${ }^{16}$ a UE possui competência apenas para desenvolver ações de apoio, de coordenação ou de complemento ${ }^{17}$, não dispondo de poder legislativo nesse domínio.

Todavia, os cuidados de saúde ainda são, em princípio, uma matéria de competência nacional e não europeia. O Tratado estabelece que cabe aos EstadosMembros definir as respectivas políticas de saúde e organizar e assegurar a prestação dos serviços de saúde e dos cuidados médicos, incluindo a gestão dos serviços e os recursos que lhes são necessários, e que a UE respeitará inteiramente essa responsabilidade (Art. 168, §7).

Dessa forma o leque de Instituições da União Europeia que atuam em matéria de saúde se divide entre aquelas com poder de legislar de forma compartilhada, e aquelas responsáveis pela execução, apoio ou complementação das políticas de proteção de saúde.

Assim o Parlamento Europeu em conjunto com o Conselho, podem, através de do processo de legislação ordinária, adotar:

\footnotetext{
${ }_{14}$ Art. 4, 2, k do Tratado da União Europeia e Art.l-14, k do Tratado sobre Funcionamento da União Europeia.

15 "UE e os Estados-Membros estão habilitados a adoptar actos vinculativos nesses domínios. Contudo, os Estados-Membros só podem exercer a sua competência na medida em que a UE não tenha exercido a sua ou tenha decidido não o fazer". Disponível em http://europa.eu/legislation summaries/institutional affairs/treaties/lisbon treaty/ai0020 pt.htm Aceso em 20/06/2015.

${ }^{16}$ Art. 6, a do Tratado da União Europeia e Art. I-17, a do Tratado sobre Funcionamento da União Europeia.

17 "UE só pode intervir para apoiar, coordenar ou completar a ação dos Estados-Membros. Não dispõe de poder legislativo nestes domínios e não pode interferir no exercício destas competências, reservadas aos Estados-Membros." Disponível em http://europa.eu/legislation summaries/institutional affairs/treaties/lisbon treaty/ai0020 pt.htm Aceso em 20/06/2015.
} 
Art. 168, §4: [...] a) Medidas que estabeleçam normas elevadas de qualidade e segurança dos órgãos e substâncias de origem humana, do sangue e dos derivados do sangue;

b) Medidas nos domínios veterinário e fitossanitário que tenham diretamente por objetivo a proteção da saúde pública;

c) Medidas que estabeleçam normas elevadas de qualidade e de segurança dos medicamentos e dos dispositivos para uso médico. (Grifo nosso)

Sobre essas matérias podem adotar Regulamentos ${ }^{18}$ ou Diretivas ${ }^{19}$, uma vez que o

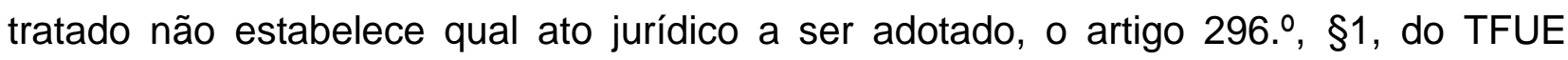
estabelece que as instituições escolhem o tipo de ato a adotar caso a caso, respeitando o princípio da proporcionalidade.

Entretanto, como determina o Tratado, a competência legislativa do Parlamento Europeu em conjunto com o Conselho está limitada a adoção de Diretivas, em relação as:

Art. 168, §5: [...]medidas de incentivo destinadas a proteger e melhorar a saúde humana, e nomeadamente a lutar contra os grandes flagelos transfronteiriços, medidas relativas à vigilância das ameaças graves para a saúde com dimensão transfronteiriça, ao alerta em caso de tais ameaças e ao combate contra as mesmas, bem como medidas que tenham por objetivo direto a proteção da saúde pública relativamente ao tabagismo e ao alcoolismo [...] (Grifo nosso).

O Parlamento Europeu, é eleito diretamente, representa os cidadãos da UE nos 28 Estados-Membros da União Europeia, por um período de cinco anos. Possui uma Comissão do Ambiente, da Saúde Pública e da Segurança Alimentar (Comissão ENVI), que conta com 69 parlamentares que trabalham para melhorar a prestação de informação aos consumidores sobre os gêneros alimentícios, nomeadamente mediante a regulamentação da rotulagem e da colocação dos produtos no mercado. A Comissão ENVI propõe e analisa propostas europeias para questões de saúde pública. Uma vez concluído em sede de comissão, o processo é votado em sessão plenária.

\footnotetext{
18 Tem caráter geral, é obrigatório em todos os seus elementos e diretamente aplicável, devendo ser integralmente respeitado por todas as entidades. O regulamento visa garantir a aplicação uniforme do direito da União em todos os Estados-Membros.

19 Vincula os Estados-Membros quanto ao resultado a alcançar, mas deixa às instâncias nacionais a competência quanto à forma e aos meios. O legislador nacional deve adotar um ato de transposição ou «medida nacional de execução» para o direito interno, que adapte o direito nacional aos objetivos fixados na diretiva.
} 
O Conselho da União Europeia ademais de participar no processo legislativo com o Parlamento pode, a partir de proposta da Comissão adoptar recomendações ${ }^{20}$ no que se refere a Saúde Pública (Art. 168. §6).

O Conselho representa os governos nacionais através de seus Ministros, com uma presidência rotativa entre os Estados-Membros; é uma entidade jurídica única, mas reúne-se em 10 'formações' diferentes de acordo com o assunto a tratar. Dessa forma, 0 Conselho EPSCO (Emprego, Política Social, Saúde e Consumidores) tem por missão aumentar os níveis de emprego e melhorar as condições de vida e de trabalho, assegurando um elevado nível de saúde humana e de defesa dos consumidores na UE. Essa Instituição com o clássico conceito de órgão intergovernamental com caráter representativo não prevê mecanismos de participação social em suas atividades.

A Comissão Europeia, compota por Comissários de 28 Estados-Membros, com mandato de 5 anos, tem entre suas funções propor legislação acima mencionados, podendo também:

1) executar ações complementares no que se refere a 'melhoria da saúde pública' e na "prevenção das doenças e afecções humanas e na redução das causas de perigo para a saúde física e mental", incluindo "a luta contra os grandes flagelos, fomentando a investigação sobre as respectivas causas, formas de transmissão e prevenção, bem como a informação e a educação sanitária e a vigilância das ameaças graves para a saúde com dimensão transfronteiriça, o alerta em caso de tais ameaças e o combate contra as mesmas" e "na redução dos efeitos nocivos da droga sobre a saúde, nomeadamente através da informação e da prevenção” (Art. 168, §1).

2) apoiar e coordenar a "cooperação entre os Estados-Membros" em matéria de Saúde Pública, "a fim de aumentar a complementaridade dos seus serviços de saúde nas regiões fronteiriças", através de iniciativas para "definir orientações e indicadores, organizar o intercâmbio das melhores práticas e preparar os elementos necessários à vigilância e à avaliação periódicas” (Art. 168, § 2).

3) Apoiar a "cooperação com os países terceiros e as organizações internacionais competentes no domínio da saúde pública” (Art. 168, §3).

\footnotetext{
20 Não possuem efeito vinculante, sugerem uma linha de conduta sem impor uma obrigação legal aos seus destinatários
} 
Para executar essas atividades relacionadas a saúde, a Comissão Europeia possui uma Direção Geral de Saúde e Segurança Alimentar que acompanha a implementação das normas adotadas pela EU; analisa o impacto na saúde de outras políticas europeias em áreas afins, tais como o comércio, a concorrência e o ambiente, realizando consultas extensas; e apoiam as administrações nacionais e regionais.

O quadro 3 procura resumir as atividades dessas instituições:

Quadro 3 - Competência em matéria de saúde na União Europeia

\begin{tabular}{|c|c|c|c|c|}
\hline $\begin{array}{c}\text { Disposi } \\
\text { tivo }\end{array}$ & Temas de competência & Natureza & Instituição & Ato \\
\hline \multirow[b]{3}{*}{$168, \S 1$} & \multirow{3}{*}{$\begin{array}{l}\text { Melhoria da saúde pública } \\
\text { Prevenção das doenças e afecções } \\
\text { humanas } \\
\text { Redução das causas de perigo para a } \\
\text { saúde física e mental. } \\
\text { Luta contra os grandes flagelos, } \\
\text { fomentando a investigação sobre as } \\
\text { respectivas causas, formas de } \\
\text { transmissão e prevenção, informação } \\
\text { e a educação sanitária e a vigilância } \\
\text { das ameaças graves para a saúde } \\
\text { com dimensão transfronteiriça, o alerta } \\
\text { em caso de tais ameaças e o combate } \\
\text { contra as mesmas. } \\
\text { Redução dos efeitos nocivos da droga } \\
\text { sobre a saúde, nomeadamente através } \\
\text { da informação e da prevenção. }\end{array}$} & \multirow[t]{3}{*}{ Complementar } & Comissão & $\begin{array}{l}\text { Executar } \\
\text { políticas e } \\
\text { Atos do } \\
\text { Conselho }\end{array}$ \\
\hline & & & Conselho & $\begin{array}{l}\text { Recomen } \\
\text { dações }\end{array}$ \\
\hline & & & Parlamento & \\
\hline \multirow[b]{3}{*}{$168, \S 2$} & \multirow{3}{*}{$\begin{array}{l}\text { Incentivar a cooperação entre os } \\
\text { Estados-Membros nos domínios a que } \\
\text { se refere o presente artigo; } \\
\text { Incentivar a cooperação entre os } \\
\text { Estados-Membros a fim de aumentar a } \\
\text { complementaridade dos seus serviços } \\
\text { de saúde nas regiões fronteiriças. } \\
\text { Tomar Iniciativas adequadas para } \\
\text { promover essa coordenação, } \\
\text { nomeadamente iniciativas para definir } \\
\text { orientações e indicadores, organizar o } \\
\text { intercâmbio das melhores práticas e } \\
\text { preparar os elementos necessários à } \\
\text { vigilância e às avaliações periódicas. }\end{array}$} & \multirow[t]{3}{*}{$\begin{array}{l}\text { Apoio e } \\
\text { Coordenação }\end{array}$} & Comissão & $\begin{array}{l}\text { Executar } \\
\text { políticas e } \\
\text { Atos do } \\
\text { Conselho }\end{array}$ \\
\hline & & & Conselho & $\begin{array}{l}\text { Recomen } \\
\text { dações }\end{array}$ \\
\hline & & & Parlamento & \\
\hline \multirow[t]{2}{*}{$168, \S 3$} & \multirow[t]{2}{*}{$\begin{array}{l}\text { Fomentar a cooperação com os países } \\
\text { terceiros e as organizações } \\
\text { internacionais competentes no domínio } \\
\text { da saúde pública. }\end{array}$} & \multirow[t]{2}{*}{ Apoio } & Comissão & $\begin{array}{l}\text { Executar } \\
\text { políticas e } \\
\text { Atos do } \\
\text { Conselho }\end{array}$ \\
\hline & & & Conselho & \\
\hline
\end{tabular}




\begin{tabular}{|c|c|c|c|c|}
\hline & & & Parlamento & - \\
\hline \multirow[b]{3}{*}{$168, \S 4$} & \multirow{3}{*}{$\begin{array}{l}\text { a) Medidas que estabeleçam normas } \\
\text { elevadas de qualidade e segurança } \\
\text { dos órgãos e substâncias de origem } \\
\text { humana, do sangue e dos derivados } \\
\text { do sangue; essas medidas não podem } \\
\text { obstar a que os Estados-Membros } \\
\text { mantenham ou introduzam medidas de } \\
\text { proteção mais estritas; } \\
\text { b) Medidas nos domínios veterinário e } \\
\text { fitossanitário que tenham diretamente } \\
\text { por objetivo a proteção da saúde } \\
\text { pública; } \\
\text { c) Medidas que estabeleçam normas } \\
\text { elevadas de qualidade e de segurança } \\
\text { dos medicamentos e dos dispositivos } \\
\text { para uso médico. }\end{array}$} & \multirow[t]{3}{*}{ Compartilhada } & Comissão & $\begin{array}{l}\text { Propor } \\
\text { legislação }\end{array}$ \\
\hline & & & Conselho & $\begin{array}{l}\text { Regulame } \\
\text { nto } \\
\text { Diretiva }\end{array}$ \\
\hline & & & Parlamento & $\begin{array}{l}\text { Regulame } \\
\text { nto } \\
\text { Diretiva }\end{array}$ \\
\hline \multirow[b]{3}{*}{$168, \S 5$} & \multirow[b]{3}{*}{$\begin{array}{l}\text { Adotar medidas de } \text { incentivo } \\
\text { destinadas a proteger e melhorar a } \\
\text { saúde humana, e nomeadamente a } \\
\text { lutar contra os grandes flagelos } \\
\text { transfronteiriços, medidas relativas à } \\
\text { vigilância das ameaças graves para a } \\
\text { saúde com dimensão transfronteiriça, } \\
\text { ao alerta em caso de tais ameaças e } \\
\text { ao combate contra as mesmas, bem } \\
\text { como medidas que tenham por } \\
\text { objetivo direto a proteção da saúde } \\
\text { pública relativamente ao tabagismo e } \\
\text { ao alcoolismo (com exclusão de } \\
\text { qualquer harmonização das } \\
\text { disposições legislativas do da Estados- } \\
\text { regulamentares dos } \\
\text { Membros) }\end{array}$} & \multirow[t]{3}{*}{ Compartilhada } & Comissão & $\begin{array}{l}\text { Propor } \\
\text { legislação }\end{array}$ \\
\hline & & & Conselho & Diretiva \\
\hline & & & Parlamento & Diretiva \\
\hline \multirow{3}{*}{$168, \S 6$} & \multirow{3}{*}{$\begin{array}{l}\text { Assegurar um elevado nível de } \\
\text { proteção da saúde na definição e } \\
\text { execução de todas as políticas e } \\
\text { ações da União }\end{array}$} & & Comissão & $\begin{array}{l}\text { Propor } \\
\text { Recomen } \\
\text { dações }\end{array}$ \\
\hline & & & Conselho & $\begin{array}{l}\text { Recomen } \\
\text { dações }\end{array}$ \\
\hline & & & Parlamento & \\
\hline
\end{tabular}

Fonte: Tratado da União Europeia e Tratado sobre o Funcionamento da União Europeia ${ }^{21}$

Dentro da UE, existem outras importantes instituições de saúde, Agências descentralizadas que desempenham funções técnicas, científicas ou administrativas,

${ }^{21}$ Jornal Oficial da União Europeia. Versões consolidadas do tratado da União Europeia e do tratado sobre o funcionamento da União Europeia. Jornal Oficial da União Europeia. Lisboa, 408 p. 2010. Disponível em: < http://europa.eu/pol/pdf/consolidated-treaties_pt.pdf >. Acesso em: 09 jul. 2014. 
assistindo as instituições da UE na elaboração e aplicação das políticas matéria de saúde; apoiam a cooperação entre a UE e os governos nacionais, reunindo competências técnicas especializadas das instituições europeias e das autoridades nacionais e Agências de execução que apoiam a Comissão Europeia na gestão dos programas da UE:

- Agência Europeia para a Segurança e a Saúde no Trabalho (EU-OSHA)

- Centro Europeu de Prevenção e Controlo das Doenças (ECDC)

- Autoridade Europeia para a Segurança dos Alimentos (EFSA)

- Fundação Europeia para a Melhoria das Condições de Vida e de Trabalho (EUROFOUND)

-Agência Europeia de Medicamentos (EMA)

- Agência de Execução para os Consumidores, a Saúde, a Agricultura e a Alimentação (CHAFEA) 22

Não detalharemos nesse trabalho a competência e formas de atuação dessas, uma vez que a proposta inicial busca verificar exclusivamente aquelas instituições cujas competências são estabelecidas nos tratados constitutivos do bloco. Entretanto, vale ressaltar que, mesmo com os organismos regionais fortes, seus esforços muitas vezes podem ser frustrados devido ao fato de que a saúde é uma competência compartilhada em que os Estados-Membros ainda têm alavancagem dominante. Esta tampouco é facilitada pelo fato de que vários Estados pussuem diferentes sistemas de saúde e respondem de forma diferente aos vários desafios da saúde .

Ao que pese certa evolução democrática com o Tratado de Lisboa, ao incluir o Parlamento no processo de elaboração das normas da EU, inclusive naquelas relacionadas à saúde, observa-se e questiona-se o grau de participação dos cidadãos frente as demais Instituições, incluindo tais agências, e nos próprios processos que definem as políticas de saúde no Parlamento e Conselho.

\footnotetext{
22 https://osha.europa.eu/pt; http://ecdc.europa.eu/en/Pages/home.aspx; http://www.efsa.europa.eu/; http://www.eurofound.europa.eu/pt; http://www.ema.europa.eu; http://ec.europa.eu/chafea
} 


\section{Instituições que atuam em Saúde na União das Nações Sul-americanas}

A União das Nações Sul-americanas (Unasul) é uma iniciativa de integração regional 'puramente intergovernamental' (14) que associa os 12 países sul-americanos. Expressa por seu Tratado Constitutivo o objetivo em construir, de maneira participativa e consensuada, um espaço de integração e união cultural, social, econômico e político, outorgando prioridade ao diálogo político, às políticas sociais, à educação, à energia, infraestrutura, financiamento e meio ambiente entre outros, com vistas a eliminar a desigualdade socioeconômica, lograr a inclusão social e a participação cidadã, fortalecer a democracia e reduzir as assimetrias, fortalecendo a soberania e independência dos Estados.

Ventura e Baraldii (15) apontam que a Unasul constitui 'um âmbito de integração política que abarca a energia, a infraestrutura, a segurança e a cidadania'. Ou seja, compreende a integração como uma totalidade e não só através de uma perspectiva puramente econômica, como foram pensados historicamente os organismos regionais tradicionais, tanto nesta região como em outras ao redor do mundo.

$\mathrm{O}$ art. 3 do Tratado Constitutivo aponta como um dos objetivos específicos "j) o acesso universal à seguridade social e aos serviços de saúde" e "u) a cooperação setorial como um mecanismo de aprofundamento da integração sul-americana, mediante o intercâmbio de informação, experiências e capacitação".

Com uma estrutura mínima, mas nem por isso simples, a Unasul é marcada pelo caráter intergovernamental na tentativa de promover a cooperação internacional a partir do consenso de prioridades entre os estados membros. Como parte da institucionalidade da Unasul há a previsão de criação de Conselhos de nível Ministerial, Grupos de Trabalho e outras instâncias institucionais que sejam requeridas, de natureza permanente ou temporária (Art. 5, Tratado Constitutivo).

As decisões adotadas pelos Chefes de Estado, e acordos e resoluções dos Ministros de em seus respectivos Conselhos são a base normativa para a Unasul. Ressalta-se que dado seu caráter intergovernamental, para serem obrigatórios, as decisões dos Chefes de Estado, precisam ser incorporados no ordenamento jurídico nacional (Art. 12, Tratado Constitutivo Unasul). 
No âmbito da Unasul, foi criado, em dezembro de 2008, o Conselho de Saúde Sulamericano (Unasul-Saúde), formado pelos Ministros de Estado de Saúde dos países membros e com o objetivo de consolidar a América do Sul como um espaço de integração em saúde, contribuindo para o objetivo de se alcançar saúde e desenvolvimento para todos, com perspectiva de incorporar ações e avanços já logrados com espaços anteriores:

De este modo, el consejo ha venido canalizando los logros alcanzados en otros esquemas de integración con el fin de promover políticas comunes y actividades coordinadas entre los países miembros de la UNASUR. (16)

El Consejo de Salud Suramericano tiene como Objetivos Generales: Consolidar Suramérica como un espacio de integración en Salud que contribuya a la Salud para Todos y al desarrollo, incorporando e integrando los esfuerzos y logros subregionales de MERCOSUR, ORAS CONHU y OTCA. (Art. 5 UNASUR, 2008b).

The ministers, through the Health Council or the Council for Social Development, have the duty to implement the standards adopted. The decision-making mode within UNASUR is still very loose, partly because it builds on regional entities that were already in place. The entity is firmly inter-governmental and nations remain entrenched in their national approaches to common challenges. (6)

O Conselho de Saúde estabelece cinco áreas prioritárias de ação em saúde: (1) escudo epidemiológico; (2) desenvolvimento dos sistemas de saúde universal; (3) acesso universal a medicamentos; (4) promoção da saúde e ação sobre os determinantes sociais; e (5) Desenvolvimento e gestão de recursos humanos em saúde (Agenda Sul-Americana de Saúde).

A premissa desse Conselho é que a saúde é um direito fundamental do ser humano. Para alcançar o objetivo de reduzir as iniquidades regionais com a efetivação do direito à saúde, o Conselho Sul-Americano de Saúde se estrutura a partir de Grupos Técnicos de acordo com as cinco linhas de ação prioritárias e Redes Estruturantes. 
Os Grupos Técnicos (GTs) são compostos pelas respectivas áreas técnicas e pontos focais a nível ministerial dos países, e uma coordenação principal e uma alternada, que são exercidas por dois países que revezam anualmente os papéis ${ }^{23}$.

As Redes Estruturantes da Unasul-Saúde ${ }^{24}$ são conformadas por instituições ou representantes indicados pelos Ministérios de Saúde dos países membros (Art. 4, Res. 07/2009, CSS), com capacidade de contribuir para o desenvolvimento de sistemas e serviços de saúde ou de formar profissionais de saúde e gerir os conhecimentos que facilitem a tomada de decisões no interior dos sistemas de saúde (9). Essas redes, como espaços de cooperação técnica em áreas da saúde pública, são geridas por uma instituição de cada campo especifico, indicada pelos países a aprovadas pelo GT de Recursos Humanos membros (Art. 6, Res. 07/2009, CSS) e elaboram seus respectivos planos de trabalho com ações e projetos definidos.

Ao que pese o esforço na definição dos planos e condução das ações pactuadas tanto nas Redes como nos GTs, a constante alternância dos pontos focais indicados pelos países, a falta de orçamento destinado pela Unasul a essas atividades e a delonga do Conselho em adotar os Estatutos das Redes ${ }^{25}$ constituem-se fenômenos para a discussão quanto a relevância e compromisso político dos países envolvidos nesse modelo de integração sanitária.

\begin{abstract}
Si bien encontramos respaldo legal en el tratado constitutivo y en los respectivos estatutos de los consejos y grupos de trabajo, su trabajo carece de seguimiento y obligatoriedad legal, de manera que su actuar esté subordinado a una reglamentación clara y eficiente. Siguen existiendo, por lo tanto, elementos de improvisación y espontaneidad en el actuar de esta nueva institucionalidad. (Siendo quizás, precisamente esto, lo que se requiere de acuerdo al estado actual de las relaciones recíprocas entre los países de la región). (7)
\end{abstract}

\footnotetext{
${ }^{23}$ GT Vigilância e Resposta é coordenado por Uruguai/Paraguai; GT Sistemas de Saúde Universais por Chile/Bolívia (Res. 08/2009); GT Medicamentos por Argentina/Suriname; Promoção e Determinantes Sociais por Colômbia/Venezuela; e GT Desenvolvimento de Recursos Humanos por Brasil/Peru (Res. 04/2009).

${ }^{24}$ Resolução 07/2009, CSS. Redes Criadas: RETS, RINS, RESP, RINC. Rede ORHIS criada pela Resolução 10/2009.

${ }^{25}$ Regulamento da RETS proposto em novembro de 2013 até o presente (julho/2015) ainda não aprovado pelo Conselho de Saúde.
} 
A criação do Instituto Sul-Americano de Governo em Saúde (ISAGS), como instituição permanente da Unasul ${ }^{26}$, merece destaque por ter como objetivo a promoção de intercâmbio de boas práticas e evidências, reflexão crítica, gestão do conhecimento e geração de inovações no campo da política e 'devendo fomentar e oferecer insumos para a governança da saúde nos países da América do Sul e sua articulação regional na saúde global' (14).

Ao longo dos curtos anos da Unasul-Saúde foram adotadas várias resoluções, incluindo: Plano Quinquenal de Saúde, influenza AH1N1, estratégia regional contra a

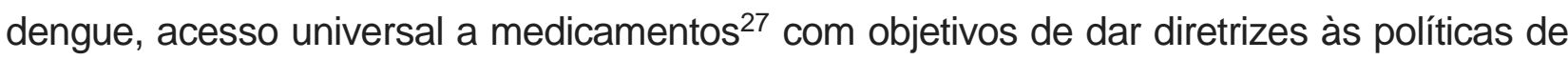
saúde no âmbito regional e influenciar as ações locais, entretanto, observa-se a necessidade de ampliação de mecanismos para garantir, no âmbito da Unasul, sua efetiva implementação.

Compliance by national authorities with regional social rules and policies is a key aspect of social policy effectiveness. It does not only entail that countries sign up to regional treaties and protocols that relate to social aspects. It also demands the existence of robust implementation and monitoring mechanisms that are put in place at the national and regional levels to ensure that regional social policies are truly being promoted and implemented (6)

Outro ponto importante que voltamos a destacar é a questão sobre a participação social neste bloco $^{28}$. Ainda que constituído como espaço de integração política e com a necessidade de incorporação interna das decisões oriundas desse, normalmente através dos parlamentos nacionais, tal objetivo específico do bloco (art. 3.p) e no que se refere aos temas de saúde ${ }^{29}$ (art. 4, g. CSS) dita participação não é vislumbrada em nenhum dos processos e instituições acima descritos.

\footnotetext{
${ }^{26}$ Resolução 05/2009.

${ }^{27}$ Resoluções 01/2009; 02/2009; 03/2009; 09/2009.

28 Artigo 18 Participação Cidadã Será promovida a participação plena da cidadania no processo de integração e união sul-americanas, por meio do diálogo e da interação ampla, democrática, transparente, pluralista, diversa e independente com os diversos atores sociais, estabelecendo canais efetivos de informação, consulta e seguimento nas diferentes instâncias da UNASUL. Os Estados Membros e os órgãos da UNASUL gerarão mecanismos e espaços inovadores que incentivem a discussão dos diferentes temas, garantindo que as propostas que tenham sido apresentadas pela cidadania recebam adequada consideração e resposta.

29 Art 4, CSS g) Promover la responsabilidad y la participación ciudadana en los temas de la Salud, en cuanto bien público que atañe al conjunto de la sociedad la incorporación de las organizaciones sociales y comunitarias en UNASUR Salud;
} 
Por outro lado, não foram encontrados nos documentos da UNASULSaúde mecanismos de controle e participação social. Esta ausência surpreende não apenas diante dos princípios do SUS, mas também diante das características da própria UNASUL: é pouco provável que outro tratado constitutivo de uma organização internacional mencione tantas vezes a participação social, chegando a erigi-la como objetivo específico do bloco (15).

\section{A Democracia nessas Instituições}

Tanto o Conselho de Saúde da Unasul como Conselho da UE incorporaram o clássico conceito de órgão intergovernamental com caráter representativo, uma vez que os membros desses órgãos deliberam na qualidade de representantes dos Estadosmembros. Nota-se que os membros dos respectivos Estados são indicados por esses conforme a matéria a tratar, as circunstâncias do momento, a defesa dos interesses nacionais, entre outros. Sendo assim, aqueles que arcarão com os efeitos das decisões tomadas nos citados Conselhos, não tiveram a chance de participar, debater e decidir qual caminho a ser trilhado.

O déficit democrático é evidente quando não se possibilita ao cidadão refletir sobre determinada questão, independentemente do grau de relevância dessa, uma vez que muitos dos debates travados nessas arenas, sobretudo em matéria de saúde, são de interesses dos cidadãos dos Estados-membros.

A população além de não ter a chance de debater a proposta em tela, recebe e tem que cumprir os resultados, assim como as consequências advindas daquela, quer sejam positivas ou negativas. O vazio de participação existente entre uma proposta levantada por um Estado-membro até a efetiva materialização de uma política comum regional prejudica todo o processo de integração.

Outro aspecto preocupante que ocorre na UE, e que poderíamos incluir na Unasul, está nos assuntos regulados através de negociações interestatais, como nos GTs da Unasul, ao passo que esses são, via de regra, subtraídos a uma formação democrática da opinião e da vontade, as quais normalmente dependem de arenas nacionais. Por essa razão, afirma Habermas: "Na União Europeia, o processo decisório constitui ótimo exemplo para esse déficit democrático que surge com a transferência dos grêmios 
decisórios nacionais para as comissões interestatais, formadas por representantes dos governos" (18).

Partindo do caso europeu, Habermas (18) diagnostica então as tendências emancipatórias que apontam na direção da consolidação de instituições democráticas transnacionais, bem como seus obstáculos, ligados à possibilidade de que essas instituições se tornem formas pós-democráticas de dominação política.

\section{Conclusões}

$\mathrm{Na}$ UE, os ministérios nacionais e várias agências de saúde desempenham um papel importante na implementação das políticas e normas que são adoptadas por suas instituições. As unidades e estabelecimentos de saúde em toda a Europa Ocidental são avançados, tendo em conta as tradições do estado de bem-estar da maioria dos países, uma grande parte dos orçamentos nacionais é dedicado aos serviços de saúde nesses países. A administração de saúde também está bem desenvolvida. Isto significa que a incorporação de padrões regionais em normas nacionais tende a ser mais rápida do que na Unasul, onde as questões de recursos humanos em saúde e de infraestrutura ainda são desafios comuns, apesar dos progressos realizados nos últimos anos em países como Argentina, Brasil e Colômbia (6).

A União Europeia, bem como a Unasul requerem muito mais do que uma estrutura e alguns órgãos decisórios, antes disso, necessita de uma legitimação cidadã. Dessa forma, Habermas defende que: ' $O$ estado de cidadão do mundo deixou de ser uma simples quimera, mesmo que ainda estejamos muito longe de atingi-lo. A cidadania em nível nacional e a cidadania em nível mundial formam um continuun cujos contornos podem ser vislumbrados no horizonte' (18).

A ausência da participação popular nesses blocos produz um ambiente e um sentimento de descrença e baixo, quando não ausente, o comprometimento para a implementação e o cumprimento das decisões emanadas pelos seus órgãos.

De imediato, alerta-se para a necessidade de se entender como efetiva participação para muito além de meras consultas populares esporádicas.

Se suma a esto la necesidad de que la sociedad civil reconozca la importancia de estas negociaciones como espacios de avance para el derecho a la salud, entendiendo que para lograrlo no solo se requiere un 
buen gobierno a nivel de instancias políticas; sino también que los movimientos sociales asuman la integración en salud como una tarea prioritaria (19).

A questão da democracia passa a ser um elemento importante dentro do processo de integração, ao pressupor no próprio desenvolvimento deste a ampliação vertical das elites de cada unidade política e instituições, possibilitando o aumento da participação popular na vida pública. 


\section{Referências}

1 - Almeida C. Saúde, política externa e cooperação Sul-Sul: elementos para pensar o caso brasileiro. In: Fiocruz/IPEA/Min. da Saúde/Secretaria de Assuntos Estratégicos da Presidência da República, organizadores. A Saúde no Brasil em 2030: prospecção estratégica do sistema de saúde brasileiro: desenvolvimento, Estado e políticas de saúde. Rio de Janeiro: FIOCRUZ; 2013.

2 - Fidler DP. Health as foreign policy: Between principle and power. Whitehead Journal of Diplomacy and International Relations, v. VI, pp. 179-194, 2005.

3 - Fidler DP. Health in foreign policy: an analytical overview. Canadian Foreign Policy Journal, 2009, 5(3): 11-29. [Acesso em 21 jul de 2015]. Disponível em: Http://dx.doi.org/10.1080/11926422.2009.9673489.

4 - Instituto Suramericano de Gobierno En Salud (ISAGS). Sistemas de salud en Suramérica: desafíos para la universidad, la integralidad y la equidad. Rio de Janeiro: Isags, 2012. 854 p. Disponível em: <http://www.isagsunasur.org/uploads/biblioteca/2/bb[8]ling[2]anx[9].pdf>. Acesso em: 20 jul. 2015.

5 - Kerouedan D. Géopolitique de la santé mondiale. Fayard, Paris, 2013. [Acesso em 12 jun 2015]. Disponível em http://books.openedition.org/cdf/2291

6 - Langenhove LV, Kingah S. Conditions for Effective Regional Social (Health) Policies: The EU and UNASUR Compared. Belgica: United Nations University - Institute on Comparative Regional Integration Studies, 2014. 24 p. Disponível em: $<$ http://www.cris.unu.edu/fileadmin/workingpapers/W-2014-3.pdf>. Acesso em: 20 jul. 2015.

7 - Legemaate J. Integrating health law and health policy: a European perspective. Health Policy, Holanda, n. 60, p.101-110, 2002.

8 - Castedo AZ. Derecho de la Integración Económica Regional. Banco Interamericano de Desarrollo Instituto para la Integración de América Latina Bid-Intal. Buenos Aires, 1989.

9 - Buss PM, Ferreira JR. Cooperação e integração regional em saúde na América do Sul: a contribuição da Unasul-Saúde. Ciênc. saúde coletiva, 2011, 16(6): 2699-2711. [Acesso em 25 jul 2015]. Disponível em http://www.scielo.br/scielo.php?script=sci_arttext\&pid=S1413$81232011000600009 \& \operatorname{lng}=\mathrm{en} \& \mathrm{nrm}=$ iso

10 - Hervey, Tamara K.; McHALE, Jean V. Health Law and the European Union. Inglaterra: Cambridge University Press, 2004. 469 p. 
11 - Grove-Valdeyron, Nathalie de. Droit européen de la santé. Paris: L.G.D.J, 2013. 209 p.

12 - Bélanger M. Éléments de doctrine en droit international de la santé (écrits 1981 2011). Bordeaux: les Études hospitalières, 2012

13 - Ventura D. Saúde Pública e Integração Regional: tensões entre o direito à saúde e o comércio internacional. In: Armin, VB, Flávia P, Mariela MA, organizadores. Direitos Humanos, Democracia e Integração Jurídica na América do Sul. Rio de Janeiro: Max Planck Institute/Lumen Juris/PUC-SP; 2011.

14 - Ventura D. Saúde pública e política externa brasileira. Sur - Revista Internacional de Direitos Humanos. 2013, 10(19).

15 - Ventura D, Baraldii C. A UNASUL e a nova gramática da integração sulamericana. Brasil no Mundo, 2014. [Acesso em 06 jul 2015]. Disponível em: $<$ http://fes.org.br/brasilnomundo/wp-content/uploads/2014/06/ventura-baraldi-unasulpontes.pdf

16 - Racovschik MA. Consejos de la UNASUR: origen, funciones y perspectivas. Observatorio de la UNASUR, FLACSO, 2010. [Acesso em 06 jul 2015]. Disponivel em: http://observatoriounasur.files.wordpress.com/2010/07/consejos-de-la-unasur1.pdf

17 - Valencia D. Unión de Naciones Sudamericanas, un nuevo modelo de integración regional. Chile: Universidad de Chile; 2012.

18 - Habermas J. Sobre a Constituição da Europa: um ensaio. São Paulo: Unesp; 2012.

19 - Santos RF, Bolis M. América latina: espacios de avance en torno al derecho a la salud. In: Delduque MC et al, organizadores. El Derecho desde la Calle: Introducción Crítica al Derecho a la Salud. Brasília: CEAD UnB; 2012. 